\title{
Experimental study on incipient condition of fluidized bed sediment in oscillatory
}

\author{
Rui Wang ${ }^{1}$ and Guoliang $\mathrm{Yu}^{1, *}$ \\ ${ }^{1}$ SKLOE, CISSE, School of Naval Architecture, Ocean \& Civil Engineering, Shanghai Jiao Tong Uni- \\ versity, Shanghai 200240, China
}

\begin{abstract}
In this paper, the incipient condition of the fluidized bed sediment with different sizes and water contents were experimentally studied in an oscillatory tunnel made of acrylic boards. One-hundred experimental runs were performed with sediment samples by varying the yield stress to determine the relationship between the critical condition of incipient motion and the rheological properties of the cohesive sediments. Experimental results showed that the yield stress of the bed sediment decreased as the fluidization level increased. When the yield stress is no longer changed, the bed sediment was considered completely fluidized. In oscillatory flow, the critical shear stress decreases with the increase of fluidization level. When the bed sediment reaches the full fluidization state, the critical shear stress of the bed sediment at the bottom remained constant. For cohesive sediments, in the case that particle size and bulk density were known, the relationship between the yield stress and the critical shear stress was analyzed, and the incipient condition of the cohesive sediment under oscillatory flow action was determined.
\end{abstract}

\section{Introduction}

The sediment movement in oscillatory flows, such as in the waves or tides near bed, is an important topic in the research on estuary and coastal morphology. It is the basis for studying the evolution of delta, the change of seabed, the foundation of shoreline and the construction of coastal protection engineering [1,2]. Almost all sediment-related problems in water, including water quality and pollution, scouring, deposition, and issues related to construction and management of reservoirs and canals, and wetland restoration, are associated with the critical conditions of sediment motion [3, 4].

There were many studies on the incipient condition of cohesive sediment bed in steady flows and some of them emphatically studied the relationship between fluidization level and the incipient condition of cohesive sediment [5-7]. Presently, the study on incipient condition of cohesive sediment bed in oscillatory flows. Literautres [8-10] did not take the effect of the fluidization level on the incipient conditions in oscillatory flows into account. However, according to $[11,12]$, the apparent viscosity, shear stress and yield stress of natural coastal cohesive bed would vary with oscillatory shear loadings. Cohesive sediments belong to the non-newton fluid of which the viscosity is no longer a constant, and changes with shear stress

\footnotetext{
*e-mail:yugl@sjtu.edu.cn
} 
and shear rate. Hence, the incipient condition of cohesive sediment bed in steady flows would be different than that in oscillatory flow.

It's worth noting that the yield stress is the static yield stress rather than Bingham yield stress in this paper. Because if the yield stress pushed out by Bingham model was adopted, the change of yield stress couldn't be observed clearly by changing the shear load [7]. The fluidization level of cohesive sediment is related to the moisture content, the magnitude of the shear stress and the time of shear load [11]. Due to the limitations of experimental time and equipment, the shear load time and the moisture content were artificial changed to achieve the purpose of the experiment. The cohesive sediment treated by this means can be supposed to the same with the cohesive sediment in an oscillatory flow for a long time.

In this paper, the incipient velocity of cohesive sediment with different fluidization level in oscillatory flow was measured. Based on the principle of moment balance, the empirical formula to calculate yield stress by critical incipient shear stress near bed was obtained. Finally, the incipient velocity of cohesive sediment bed in steady flows was explored.

\section{Materials and methods}

\subsection{Test materials}

Four types of cohesive sediments were tested in this study. The sediments were collected from four locations, namely two shorelines of Hangzhou Bay (i.e., the Jinshan and Fengxian shorelines), a $1000 \mathrm{~m}$ deep seabed in the South China Sea, and the Yueqing port, China. The basic properties of the test sediment are summarized in Table 1.

Table 1. Basic properties of the test sediments

\begin{tabular}{lllll}
\hline Location of Sediment & Yueqing & Fengxian & Jinshan & South Sea \\
\hline Grain density $\left(\mathrm{g} / \mathrm{cm}^{3}\right)$ & 2.34 & 2.0575 & 2.3233 & 2.2 \\
Median grain size $(\mu \mathrm{m})$ & 7.8 & 16.89 & 28 & 45.85 \\
Standard deviation of Grain size $(\mu \mathrm{m})$ & 0.7 & 1.6 & 2.6 & 0.9 \\
Sorting coefficient & 1.58 & 1.85 & 2.11 & 1.8 \\
Maximum moisture content $(\%)$ & 115 & 95.55 & 40.3 & 38.39 \\
Minimum moisture content $(\%)$ & 63.39 & 51.4 & 17 & 13 \\
\hline
\end{tabular}

\subsection{Experimental setup}

The layout of the experimental apparatus is shown in Figure 1. The inner size of this Ushaped tunnel was $10 \mathrm{~m}$ long, $0.1 \mathrm{~m}$ wide, and $0.25 \mathrm{~m}$ high. The water was driven by an oscillatory motor to generate the oscillatory flow. The maximum stroke of oscillatory motor was $0.07 \mathrm{~m}$, and the rotate speed could be adjusted with a speed converter. The maximum velocity of oscillatory flow in the tunnel was up to $35 \mathrm{~cm} / \mathrm{s}$. The bed sediment with different fluidization levels were selected in the experiment. The fluidization of cohesive sediment was expressed by yield stress which was measured by the cohesive sediment rheometer. The fluidization level changed over the mixing time. During the experiments, the incipient motion of cohesive sediment was observed by a high-speed camera.

\subsection{Test procedure}

First, tap water was added into the pipe through the water inlet at the end of the tank, and the water level would flood the maximum position that the piston could reach. the sample box 


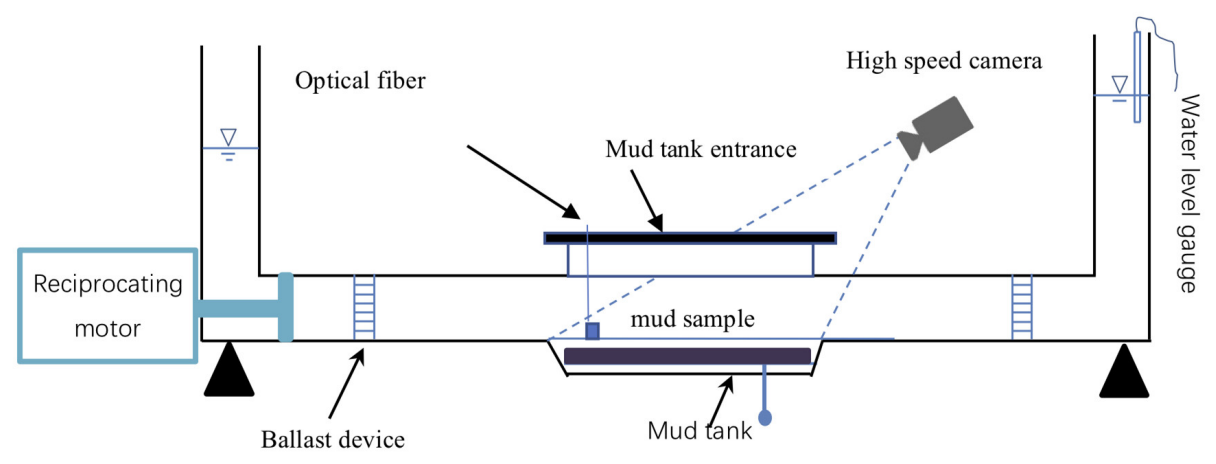

Figure 1. Illustration of the experimental setup

with the cohesive sediment samples inside was then lowered into the square box by using two threaded rods through the sample box inlet. Following this, the threaded rods were unscrewed and removed, and the seal plunger was inserted into the inlet. seal plunger was used to seal the sample inlet. Then the reciprocating motor speed controller was slowly opened, and the motion of the cohesive sediment particles was viewed through the video recorder. Reciprocating motor speed controller was knob type, When the knob turned to $100 \%$, the motor speed reaches its maximum value. In the laboratory, the speed of the reciprocating motor increased slowly at $5 \%$ per minute, until the concentration of the fiber concentration meter reaches the criterion of sediment initiation. The flow velocity was accelerated very slowly by $12 \mathrm{~cm} / \mathrm{s}$ every minute until a weak movement of the sediment particles was observed. This weak movement indicated that about 1 of the particles dislodged from the bed surface (Kramer, 1935; Chen and Wan, 1983) for which the amount of dislodged particles ranged from $3.2 \times 10^{-6} \sim 6.9 \times 10^{-5} \mathrm{~kg} \cdot \mathrm{m}^{-2} \cdot \mathrm{s}^{-1}$. This phenomenon of dislodging of particles continuously occurred on the bed surface in both time and space, i.e., the movement of particles could always be observed in the test section throughout the test [13-15]. In this study, this state of weak movement was considered as the critical state of sediment incipient motion.

\section{1. Results and analysis}

\subsection{Yield stress effect on incipient velocity of cohesive sediment}

With respect to each sample, the effect of yield stress on the incipient velocity of cohesive sediment in oscillatory was analyzed. Firstly, the yield stress and incipient velocity of the cohesive sediment which had the same median particle size with different moisture content were measured in the oscillatory flume. And then the yield stress and incipient velocity which had the same median particle size with different shear loads time were measured. Jinshan mud sample is taken as an example which is described in Figure 2 and Figure 3.

The experimental results show that: (1) With the increase of moisture content, the yield stress of sediment decreases gradually as shown in Figure 2 (a). (2) With the increase of moisture content, the yield stress decreases and the incipient velocity decreases, as shown in Figure 2 (b). (3) When the moisture content reaches the saturation level, the value of the yield stress reaches the minimum, and the corresponding incipient velocity will reach the minimum too. (4) The yield stress decreases with increasing time of shear load as shown in Figure 3 (a). After $\mathrm{t}>360 \mathrm{~s}$, the yield stress remained basically unchanged. This state is referred to fully fluidized state, as shown in Figure 3 (a). (5) The change rule of incipient velocity with 
Table 2. Basic properties of the test sediments

\begin{tabular}{llllllll}
\hline Mud sample & Jinshan mud sample & & & & \\
\hline Moisture content (\%) & 17.99 & 20.2 & 27.9 & 30.54 & 34 & 40.3 & 50 \\
Vmax (cm/s) & 27.76 & 23.66 & 20.73 & 17.12 & 10.27 & 4.81 & 4.8 \\
Yield stress (Pa) & 3720 & 2830 & 1550 & 1179 & 466 & 82 & 82 \\
\hline
\end{tabular}

where the Moisture content is the percentage of water weight to the cohesive sediment weight, $(\%)$ : Vmax is the maximum water velocity of the oscillatory when the cohesive sediments start to suspended, $\mathrm{cm} / \mathrm{s}$.

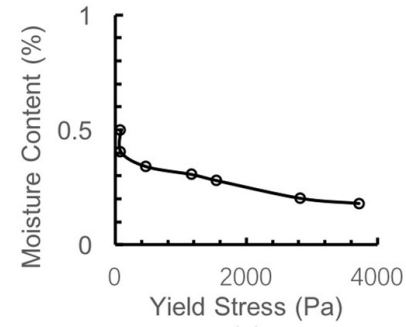

(a)

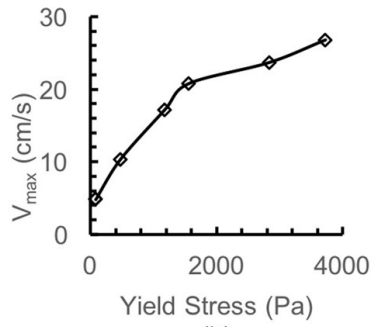

(b)

Figure 2. Yield stress of cohesive sediment with different moisture content.

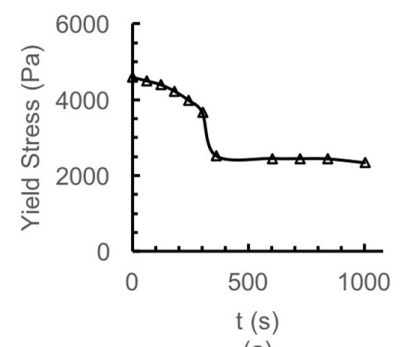

(a)

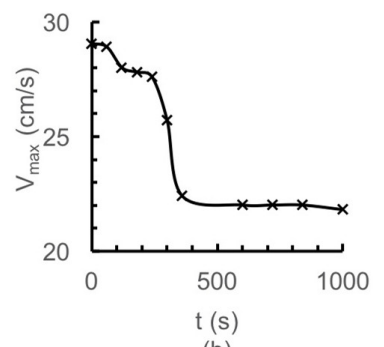

(b)

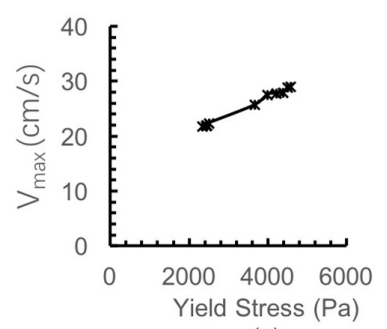

(c)

Figure 3. Yield stress of cohesive sediment with different shear loads time.

different stirring time is basically consistent with that of yield stress, as shown in Figure 3 (b) and (c).

\subsection{Relationship between incipient velocity and yield stress of cohesive sediment in oscillatory flow}

The relationship between incipient velocity and yield stress of cohesive sediment in oscillatory was analysed in this paper according to the force analysis of the cohesive sediment when the sediment particles begin to suspend. Similar with non-cohesive sediment, cohesive sediment in water also has a critical condition when it starts to suspend. The incipient condition of the non-cohesive sediment is that the torque of the uplift force $F_{L}$, drag force $F_{D}$ and gravity $W$ could keep balance which is shown as formula (1):

$$
K_{1} F_{D}+K_{2} F_{L}=K_{3} W
$$


where $K_{1}, K_{2}$ and $K_{3}$ are the torque of $F_{D}, F_{L}$ and $W$, respectively. However, the cohesive sediment particles usually do not exist in the form of individual particles, and consolidated cohesive soil is formed due to physical and chemical actions. Therefore, the influence of viscosity force $N$ on the incipient condition of cohesive sediment should be considered and the torque balance formula can be rewritten as:

$$
K_{1} F_{D}+K_{2} F_{L}=K_{3} W+K_{4} N
$$

where $K_{4}$ are the torque of $N$. The formula (2) can be further decomposed as the following aspects:

i. the cohesive force could be replaced by the yield stress, because the yield stress can characterize the viscous property [7].

ii. the bed shear stress and the drag force reach a balance when the cohesive sediments start to suspend, therefore, , and most researchers adopted the formula given by [16] to calculate the bed shear stress.

$$
\tau_{w}=\frac{1}{2} f_{b} \rho_{s} u_{0}^{2}
$$

where $\tau_{w}=$ bed shear stress; $f_{b}=$ friction coefficient of bed surface, $f_{b}=\frac{2}{\sqrt{\frac{u_{0} a_{0}}{v}}}[16], a_{0}=$ the amplitude of the oscillatory flow; $\rho=$ fluid density; $\rho_{s}=$ density of cohesive sediment; $u_{0}=u_{m} \sin \omega t$ the bed velocity and ; $u_{m}=$ The maximum flow velocity of water in the oscillatory flume when the cohesive sediments start to suspend. The bed shear stress reached the maximum when $\omega t=\frac{23}{32} \pi$, [5].

iii. According to the study of [1], the formula for can be written as formula (4)

$$
F_{L}=C_{L} \frac{\pi D_{50}^{2}}{4} \frac{\rho_{s} u_{0}^{2}}{2}
$$

where $C_{L}=$ uplift coefficient which is related to the flow around bed sediment particle, when the flow is a turbulent flow $C_{L}=$ constant.

iv. the gravity $W$ of the cohesive sediment could be negligible according to [5].

v. Another thing to note is that the yield stress is measured by rheometer and the yield stress measured by the rheometer is the overall performance of the shear stress and the measurement scale of the yield stress is larger than that of the bed shear stress [12]. The bed shear stress whose measurement scale is $\mathrm{mm}$ is relative to the bed sediment, and the concentration of the bed sediment is also very low. It could be seen from the experimental data of [11] about the yield stress and the bed shear stress in steady flow and the date measured in this paper about the yield stress and the bed shear stress in oscillatory flow that the measurement scale of the yield stress measured by rheometer is 1000 times more than that of the bed shear stress.

v. the units of $\tau_{y}$ and $\tau_{w}$ need to be unified with $F_{L}$ and $W$, because the units of $\tau_{y}, \tau_{w}$ and $F_{L}, W$ are different, so

$$
\begin{gathered}
\tau_{y}^{0}=\tau_{y} \times v^{2} \times g^{-1} / 1000 \\
\tau_{w}^{0}=\tau_{w} \times v^{2} \times g^{-1}
\end{gathered}
$$

Therefore, the equation of moment equilibrium of cohesive sediment in water could be written as

$$
u_{0}=\sqrt{\frac{2 K_{3}\left(\rho_{s}-\rho\right) \pi D_{50}^{3}+0.012 K_{4} \tau_{y} v^{2} g^{-1}}{1.5 \rho\left(4 K_{1} f_{b} v^{2} g^{-1}+K_{2} \pi D_{50}\right)}}
$$

Where $u_{0}=$ the critical incipient velocity, $m / s ; v=$ coefficient of kinematic viscosity of water, $\mathrm{m}^{2} / \mathrm{s} ; g=$ acceleration of gravity, $\mathrm{m} / \mathrm{s}^{2} ; \rho_{s}=$ the density of the cohesive sediment, $\mathrm{kg} / \mathrm{m}^{3} ; \rho=$ the density of water, $\mathrm{kg} / \mathrm{m}^{3} . K_{1}, K_{2}, K_{3}$ and $K_{4}$ are the undetermined parameters. 


\subsection{Determination of parameter values}

Nonlinear surface fitting was performed with the experimental data, and the undetermined parameters were evaluated as follows: $K_{1}=52.33 K_{2}=0.4 \times 10^{-3} K_{3}=0.36 \times 10^{-2}, K_{4}=17.58$. and the constants are evaluated as follows: This formula possesses an acceptable accuracy as $97 \%$ of the datasets are within a confidence interval with a relative error of $20 \%$, which indicated that the fit of the obtained model was fairly-good. Hence, the critical Shields parameter of the cohesive sediments is expressed in oscillatory as follows:

$$
u_{0}=\sqrt{\frac{0.72 \times 10^{-2}\left(\rho_{s}-\rho\right) \pi D_{50}^{3}+0.21 \tau_{y} v^{2} g^{-1}}{1.5 \rho\left(209.32 f_{b} v^{2} g^{-1}+0.4 \times 10^{-3} \pi D_{50}\right)}}
$$

\section{Conclusions}

The fluidization level of cohesive sediment is the main factor influencing the incipient condition of cohesive sediment in oscillatory flow. The fluidization level can be expressed by yield stress. When the cohesive is completely fluidized, the value of the yield stress achieve the minimum. The critical incipient velocity decreases with the fluidization level increases. When the cohesive sediment is completely fluidized, the value of the critical incipient velocity achieves the least. The yield stress is not only related to the fluidization level, but also to the particle size. For the cohesive sediment with the same moisture content, the yield stress increases with the decrease of particle size.

The relationship between critical incipient velocity, bed shear stress and yield stress in oscillatory flow is given in this paper. The critical incipient velocity can be calculated by median particle size $D_{50}$, particle density $\rho_{s}$ and water density $\rho$ and Yield stress $\tau_{y}$. This formula possesses an acceptable accuracy as $99 \%$ of the datasets are within a confidence interval with a relative error of $20 \%$.

\section{Acknowledgements}

This work was financially supported by the National Key Research and Development Program of China (Grant number: 2016YFC0402607). We are also grateful to the anonymous reviewers for their constructive comments and suggestions, which have helped improve the manuscript significantly.

\section{References}

[1] J.S. Ribberink, A.A. Al-Salem, Coastal engineering 25, 205 (1995)

[2] M. Moulton, S. Elgar, B. Raubenheimer, Geophysical Research Letters 41, 4628 (2014)

[3] J.G. Venditti, M. Church, S.J. Bennett, Water Resources Research 42 (2006)

[4] M. Ghose-Hajra, A. McCORQUODALE, G. Mattson, D. Jerolleman, J. Filostrat, Proceedings of the International Association of Hydrological Sciences 367, 435 (2015)

[5] C. Migniot, La Houille Blanche (1968)

[6] K. Otsubo, K. Muraoka, Journal of Hydraulic Engineering 114, 1241 (1988)

[7] M. Zhang, G. Yu, Water Resources Research 53, 7798 (2017)

[8] I.G. Jonsson, in Coastal Engineering 1966 (1967), pp. 127-148

[9] P.D. Komar, M.C. Miller, in Coastal Engineering 1974 (1975), pp. 756-775

[10] O.S. Madsen, W.D. Grant, in Coastal Engineering 1976 (1977), pp. 1092-1112 
[11] W. Yang, M. Yu, G. Yu, Journal of Coastal Research 34, 185 (2017)

[12] W. Yang, G. Yu, Journal of Waterway, Port, Coastal, and Ocean Engineering 144, 05018005 (2018)

[13] S. White, Nature 228, 152 (1970)

[14] Y.M. Chiew, G. Parker, Journal of Hydraulic Research 32, 649 (1994)

[15] S. Dey, K. Debnath, Journal of irrigation and drainage engineering 126, 255 (2000)

[16] I. Jonsson, Measurements in the turbulent wave boundary layer, in Proc. 10th Congress of IAHR (1963), Vol. 1, pp. 85-92 